Journal of Community Based Environmental Engineering and Management, 2019, Vol. 3, No. 2: 49-56

\title{
VALUASI NILAI EKONOMI WISATA PANTAI SAWARNA DENGAN MENGGUNAKAN TRA VEL COST METHOD
}

\author{
Rifki Armadinata*, Kancitra Pharmawati \\ Program Studi Teknik Lingkungan, Institut Teknologi Nasional
}

\begin{abstract}
Abstrak
Pantai Sawarna di Kabupaten Lebak memiliki keindahan alam yang dapat digunakan sebagai daya tarik objek wisata bagi setiap pengunjung. Keindahan alam pada kenyataannya tidak terhitung menjadi nilai ekonomi atau tidak memiliki nilai pasar, sehingga pentingnya dilakukan valuasi ekonomi untuk memperkecil eksternalitas yang dapat menyebabkan kegagalan pasar karena suatu barang atau jasa yang tidak memiliki nilai pasar, sehingga dalam kajian ini bertujuan untuk menentukan nilai ekonomi Pantai Sawarna dari sumberdaya alam yang tidak memiliki nilai Pasar. Metode valuasi ekonomi yang digunakan adalah metode biaya perjalanan dengan pendekatan individu (Individual Travel Cost Method). ITCM dipilih sebagai pendekatan yang lebih teliti dalam menilai kondisi sosial ekonomi pengunjung sehingga mengetahui nilai ekonomi dan nilai Willingness To Pay dari biaya perjalanan pengunjung. Willingness To Pay (WTP) dijadikan untuk mencari nilai ekonomi dan surplus konsumen area Pantai Sawarna. Hasil dari valuasi ekonomi dengan pendekatan ITCM yang digunakan di area Pantai Sawarna tersebut didapat nilai rata-rata WTP sebesar Rp. 93.672,-/pengunjung, dan nilai ekonomi Pantai Sawarna adalah Rp. 6.722.558.424,- / tahun. Nilai surplus konsumen adalah Rp. 5.164.066.252,--.
\end{abstract}

Kata kunci: Pantai Sawarna, Biaya Perjalanan, Nilai Ekonomi, Surplus Konsumen, WTP

\section{Pendahuluan}

Objek wisata merupakan salah satu tempat yang menjadikan daya tarik bagi semua orang untuk berlibur. Indonesia dikaruniai berbagai sumber daya alam yang melimpah dan banyak keindahan alam di Indonesia sudah diakui oleh dunia. Salah satu objek wisata tersebut adalah Pantai Sawarna.

Pantai Sawarna adalah sebuah pantai yang menghadap ke Samudera Hindia yang letaknya di Desa Sawarna, Kabupaten Lebak. Pantai Sawarna mulai banyak dikenal oleh wisatawan

\footnotetext{
${ }^{*}$ Penulis Korespondensi:

E-mail: rifki.armadinata7768@gmail.com

Diterima pertama kali: 23 Agustus 2019

Direvisi : 27 Agustus 2019

Disetujui untuk publikasi: 28 Agustus 2019
}

mancanegara maupun wisatawan domestik, karena Keindahan alam serta perkebunan dan goa yang mengelilingi objek wisata. Sebagian besar wilayah Pantai Sawarna berupa batu-batu karang dan memiliki gelombang laut yang cocok bagi peselancar. Potensi sumber daya alam yang merupakan keindahan Pantai Sawarna dapat menjadikan daya tarik pengunjung untuk berwisata. Keindahan daerah wisata memiliki nilai ekonomi yang dapat dihitung dengan beberapa metode valuasi (Yustiani dkk., 2017).

Pantai Sawarna memiliki nilai lingkungan yang tinggi karena keindahan alam yang alami, maka tidak salah jika Pantai Sawarna menjadi salah satu tujuan yang diminati oleh masyarakat. Nilai lingkungan tersebut terkadang tidak diperhitungkan menjadi nilai ekonomi dari objek wisata, jika penilaian terhadap keindahan alam 
tidak dilakukan maka nilai tidak terhitung atau dianggap tidak penting (Fauzi, 2004).

Keindahan alam yang menjadikan suatu keunggulan di area wisata Pantai Sawarna tidak memiliki nilai pasar atau tidak terhitung, sehingga dilakukan valuasi ekonomi untuk menilai barang dan jasa yang tidak mempunyai nilai pasar/ nilai guna yang pasti dan dapat meminimalisir dari kegagalan pasar secara langsung yang merugikan (Susilowati, 2009). Menurut Suparmoko (2014), tempat wisata adalah sebagai barang publik atau dengan kata lain bersifat milik bersama maka dapat terjadi eksternalitas yang dapat menjadikannya nilai fungsi lingkungan menjadi menurun dari tempat tersebut. Pemanfaatan dalam kontribusi nilai ekonomi di Pantai Sawarna sering terabaikan, sehingga secara kuantitatif mengenai nilai ekonomi Pantai Sawarna masih kurang (Dwiatmojo, 2015).

Metode yang dapat dilakukan untuk mengetahui nilai lingkungan dari keindahan alam sehingga dapat dimanfaatkan untuk objek wisata, dengan menghitung biaya perjalanan atau Travel Cost Method, dapat mengetahui biaya yang dikeluarkan pengunjung sebagai pendatang ke tempat objek wisata, dimana biaya yang dikeluarkan mulai dari tempat tinggal sampai tempat wisata tersebut (Fauzi, 2004). Pendekatan ini melibatkan langsung masyarakat pengunjung sebagai responden (Hasbiah dkk., 2018).

Berdasarkan permasalahan tersebut pentingnya melakukan valuasi ekonomi untuk meminimalisir terjadinya eksternalitas yang dapat menyebabkan kegagalan pasar dari suatu barang atau jasa yang tidak memiliki nilai pasar. Individual Travel Cost Method merupakan metode untuk mengetahui nilai ekonomi dari sumberdaya alam yang tidak memiliki nilai kuantitatif berdasarkan biaya perjalanan (Susilowati, 2009).

\section{Metodologi Penelitian}

Berikut adalah diagram alir penelitian, dapat dilihat pada Gambar 1.

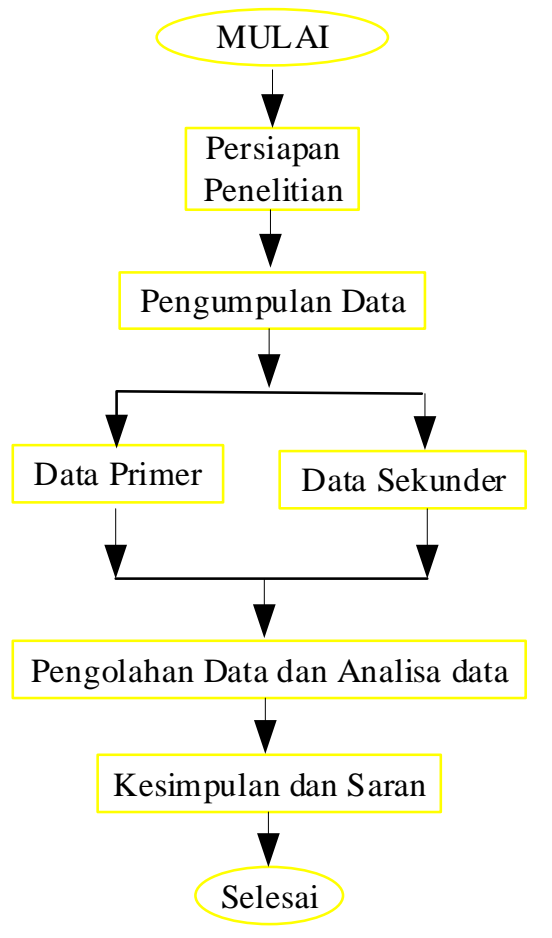

Gambar 1. Diagram Alir Penelitian

\section{Persiapan Penelitian}

Persiapan penelitian dilakukan agar tidak terdapat kendala dalam melakukan penelitian di lapangan, persiapan penelitian dibagi menjadi beberapa bagian, diantaranya : perancangan kuesioner, dengan menentukan variabel yang dapat menggambarkan sosial ekonomi pengunjung. penentuan jumlah responden menggunakan rumus slovin dengan tinggkat error $8 \%$. Penentuan tingkat error yang digunakan $8 \%$ karena tingkat kesalahan yang masih dapat di pertimbangkan dalam pemilihan responden secara acak. Dimana semakin kecil nilai toleransi maka akan menggambarkan hasil populasi yang akurat (Sugiyono, 2007).

\section{Pengumpulan Data}

Dalam penelitian ini digunakan data primer dan sekunder. 
Data primer dilakukan secara langsung terhadap objek penelitian berdasarkan dari hasil observasi lapangan dengan melakukan survei dan wawancara kuesioner, sehingga data primer yang didapatkan berupa data karakteristik sosial ekonomi pengunjung dan biaya yang dikeluarkan pengunjung.

Data sekunder didapatkan dari pihak pengelola Pantai Sawarna. Data yang diperoleh adalah jumlah pengunjung tahun 2017 pada weekday dan weekend. Jumlah pengunjung tersebut yang akan menentukan jumlah responden dengan menggunakan rumus slovin.

\section{Pengolahan dan Analisa Data}

Dalam penelitian ini dilakukan beberapa analisis, yaitu :

\section{Analisis Deskriptif}

Analisis deskriptif merupakan analisis yang menggambarkan karakteristik-karakteristik sosial dan ekonomi pengunjung, dan membantu dalam menerjemahkan terhadap pertanyaan, karena akan berpengaruh terhadap respon pengunjung dan terhadap kesediaan pengunjung dalam membayar yang diperoleh (Nugroho, 2010). Analisis deskriptif ditentukan dengan beberapa variabel-variabel yang mewakili karakteristik sosial ekonomi di Pantai Sawarna, adalah : (1) Jenis kelamin, (2) Usia, (3) Pekerjaan, (4) penghasilan, (5) Jumlah kunjungan, (6) Jarak tempuh, (7) jenis kendaraan, dan (8) tingkat Pendidikan (Nugroho, 2010).

\section{Analisis Biaya Perjalanan (Travel Cost)}

Analisis biaya perjalanan merupakan satu metode untuk mencari nilai kesediaan membayar konsumen (Willingness to pay) terhadap barang publik, dari tempat rekreasi termasuk barang publik dimana tidak mempunyai harga pasar. Permintaan jumlah pengunjung dipengaruhi oleh biaya perjalanan, hal ini juga yang mendasarkan untuk menentukan nilai suatu barang atau jasa menggunakan metode biaya perjalanan yang dikeluarkan oleh pengunjung pada saat menuju objek wisata (Djijono dkk., 2002).

Tahapan dalam melakukan Individual Travel Cost Method dengan melakukan perhitungan terhadap nilai Willingness To Pay yang akan menentukan nilai ekonomi berdasarkan biaya perjalanan. Tahapan selanjutnya menggambarkan kurva permintaan untuk menentukan hasil surplus konsumen dari grafik regresi linier yang di dapatkan antara jumlah kunjungan dengan WTP rata-rata objek wisata. Tahapan terakhir melakukan analisis regresi linier yang dapat menggambarkan hubungan antara WTP dengan variabel-variabel bebas.

\section{Hasil Dan Pembahasan}

\section{Penentuan Jumlah Responden}

Dalam penentuan jumlah responden menggunakan rumus slovin dengan standar error $8 \%$, jumlah pengujung Pantai Sawarna adalah 71.767 orang/tahun.

$\mathbf{n}(\mathbf{8 \%})=\frac{W}{1+N(\mathrm{e}) 2}=\frac{71.767}{1+71.767(0.08) 2}=156$
orang

\section{Analisis Deskriptif}

Analisis Deskriptif merupakan analisis data untuk melihat hasil dari survei yang perlu ditambahkan sebagai karakteristik untuk memudahkan dalam menggambarkan sosial ekonomi pengunjung (Nugroho, 2010).

Hasil kuesioner menunjukan bahwa pegunjung laki-laki lebih banyak dibandingkan dengan perempuan, karena pada saat pengambilan data kuesioner dicari responden yang dianggap sebagai kepala keluarga atau yang mengeluarkan biaya pada saat berkunjung. 


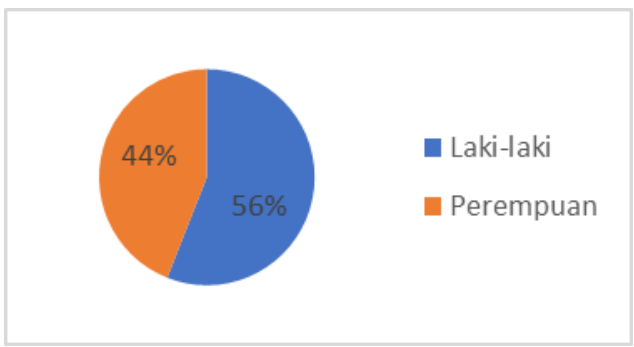

Gambar 2. Perbandingan Jenis Kelamin

Pada umumnya usia remaja cenderung lebih banyak untuk melakukan aktivitas seperti rekreasi, Sehingga banyaknya pengunjung didominasi pada rentang usia 17-23 tahun dengan persentase $62 \%$, ini karena usia remaja lebih banyak waktu yang digunakan untuk berlibur.

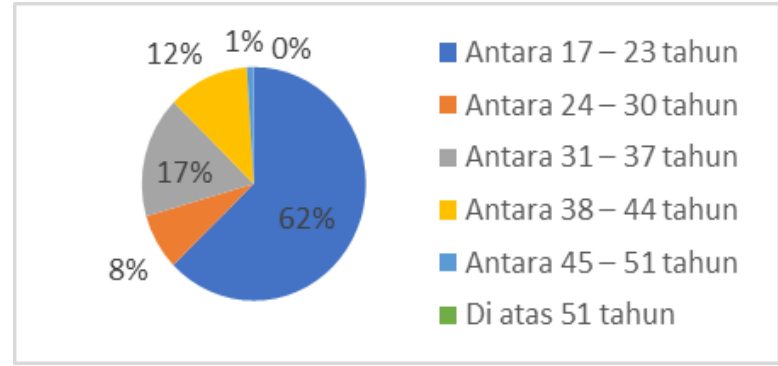

Gambar 3. Perbandingan Usia

Banyaknya waktu bekerja dan jadwal sekolah sangat berpengaruh terhadap kunjungan untuk berlibur, dimana semakin banyak waktu bekerja dan jadwal sekolah maka semakin tinggi pula tingkat rasa ingin berlibur. Banyaknya pengunjung sebagai pelajar atau mahasiswa bila dibandingkan dengan PNS dan Karyawan swasta ini karena pelajar lebih banyak waktu luang untuk berkunjung.

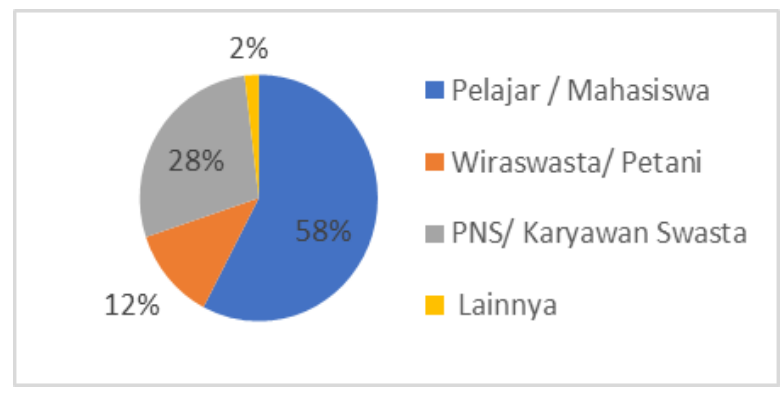

Gambar 4. Perbandingan Pekerjaan
Semakin besar penghasilan seseorang, maka semakin besar keinginan untuk berlibur. Banyaknya pengunjung didominasi oleh pelajar/mahasiswa dengan penghasilan sebagai uang saku yaitu kurang dari 1.000.000 dengan persentase $61 \%$. Dapat disimpulkan bahwa Pantai Sawarna menunjukan tempat wisata yang sangat murah sehingga banyak dikunjungi pengunjung yang penghasilannya kurang dari 1.000.000.

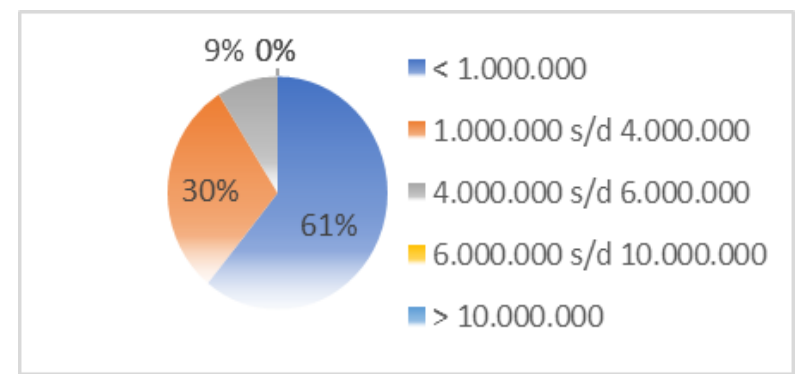

Gambar 5. Perbandingan Penghasilan

Pantai dengan keindahan alam yang asri dapat menjadikan daya tarik pengunjung untuk berwisata. Banyaknya pengunjung yang telah melakukan kunjungan 3 kali dengan persentase $30 \%$. Ini karena Pantai Sawarna sangat menarik untuk dikunjungi kembali, dimana semakin sering untuk berkunjung maka semakin kecil WTP yang akan dikeluarkan.

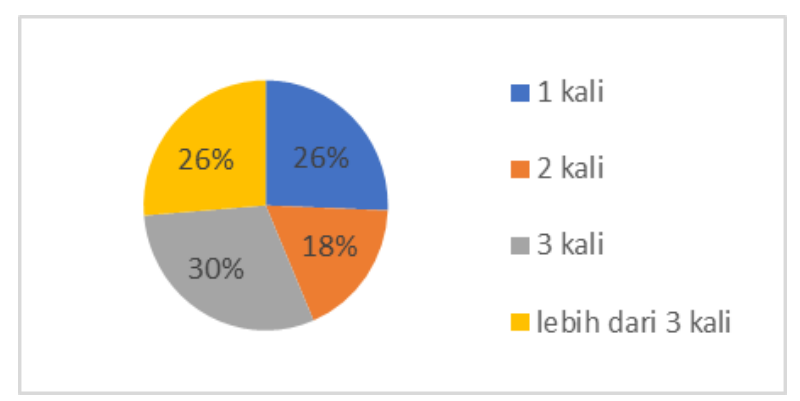

Gambar 6. Perbandingan Jumlah Kunjungan

Dekatnya tempat tinggal dengan objek wisata akan menjadikan pengunjung untuk berkunjung kembali, $25 \mathrm{~km}$ adalah jarak terdekat dari tempat tinggal dengan tempat wisata. Hasil dari penelitian banyakanya pengunjung yang tidak jauh dari tempat wisata ialah $<25 \mathrm{~km} \quad(42 \%)$, 
sehingga semakin dekat jarak tempuh untuk berkunjung semakin kecil WTP yang akan dikeluarkan.

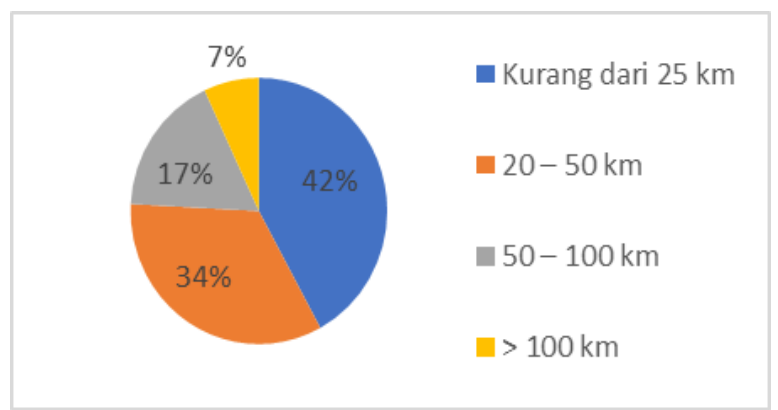

Gambar 7. Perbandingan Jarak Tempuh

Alternatif jalan yang dilalui menunju Pantai Sawarna terdapat banyaknya tanjakan dan turunan tajam, sehingga pengunjung yang sudah mengetahui medan jalan tersebut lebih memilih kendaraan sepeda motor, hal ini sesuai dengan hasil yang didapat pengendara sepeda motor dengan persentase $65 \%$ lebih banyak dibandingkan dengan kendaraan lain.

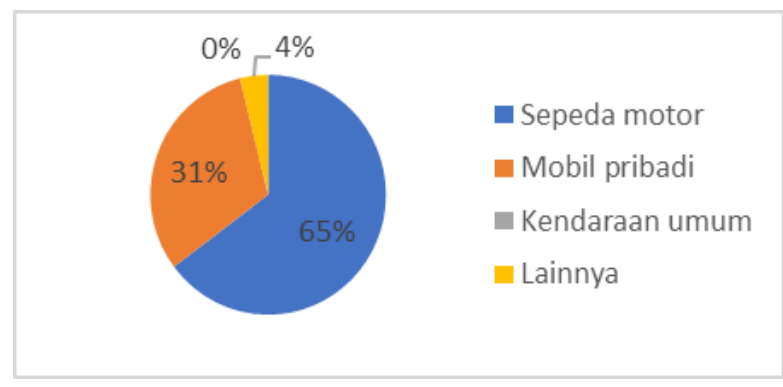

Gambar 8. Perbandingan Jenis Kendaraan

Semakin tinggi tingkat pendidikan seseorang akan semakin tinggi rasa ingin berlibur. Pengunjung Pantai Sawarna didominasi oleh lulusan atau tamat SMA dengan persentase $45 \%$, sedangkan pada perguruan tinggi adalah $32 \%$. Hal ini menunjukan bahwa tingkat pendidikan tamat SMA lebih banyak waktu untuk berlibur.

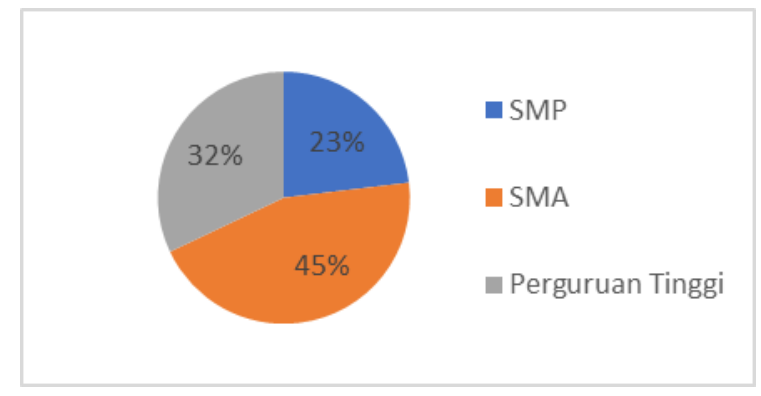

Gambar 9. Perbandingan Tingkat Pendidikan

Analisis Biaya Perjalanan

Analisis biaya perjalanan menggunakan Individual Travel Cost Method dimana metode ini untuk mencari mengetahui nilai ekonomi, surplus konsumen berdasarkan nilai WTP pengunjung.

\section{Kesanggupan Membayar (Willingness To Pay)}

Analisis biaya perjalanan dilakukan Individual Travel Cost Method penggunaan data primer dimana hasil wawancara setiap pengunjung dijadikan sebagai nilai WTP, sehingga diperoleh nilai rata-rata WTP dari jumlah responden adalah Rp. 93.672. Untuk mendapatkan nilai WTP tersebut dengan cara merata-ratakan biaya pengeluaran dengan jumlah 156 responden.

\section{Nilai Ekonomi}

Nilai ekonomi merupakan nilai yang didapatkan dari suatu barang yang dapat dihitung dengan besaran uang (rupiah). Perhitungan nilai ekonomi tertera pada Pers. 1 (Pearce, 2001)

Nilai Ekonomi $=$ Rata-rata WTP $($ rupiah $) \times$

Jumlah pengunjung/tahun

Nilai ekonomi $=$ jumlah pengunjung dalam setahun $\times$ WTP

$$
\begin{aligned}
& =71.767 \frac{\text { orang }}{\text { tahun }} \times \text { Rp. } 93.672 \\
& =6.722 .558 .424 / \text { tahun }
\end{aligned}
$$

Nilai ekonomi yang didapatkan di Pantai Sawarna Rp. 6.722.558.424. Nilai ini bisa disebut sebagai nilai yang didapatkan oleh 
pihak pengelola Pantai Sawarna selama satu tahun.

\section{Surplus Konsumen}

Gambar 10 adalah surplus konsumen wisata Pantai Sawarna.

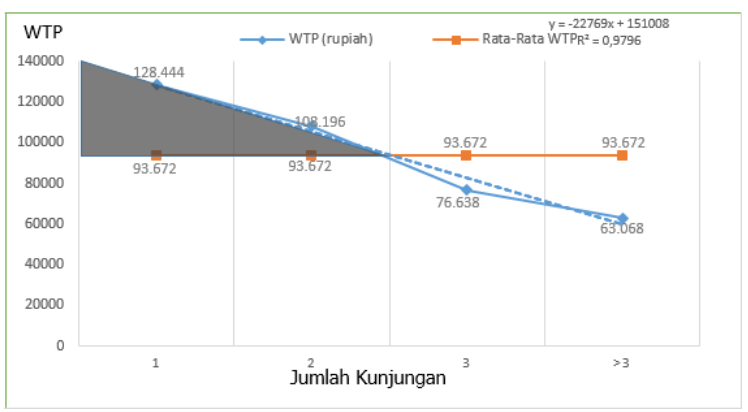

Gambar 10. Surplus Konsumen

Dari hasil perhitungan didapat nilai surplus konsumen Rp. 71.956/ pengunjung, sehingga dapat diketahui nilai surplus konsumen pertahun Pantai Sawarna adalah Rp. 5.164.066.252. Nilai surplus konsumen ini dapat dijadikan sebagai acuan pengelolaan oprasional atau pengembangan fasilitas Wisata Pantai Sawarna.

\section{Analisis Regresi Linier}

Regresi linier digunakan untuk melihat hubungan keterkaitan antara variabel bebas dengan willingness To Pay (WTP).

$$
Y=b_{0}+b_{1} X 1+b_{2} X 2+b_{3} X 3+b_{4} X 4+\cdots
$$

Dimana:

$Y=$ Willingnes To Pay (WTP)

$b_{n}=$ Koefisien Regresi

$X n=$ Variabel Terpilih

Hasil analisis yang didapatkan dapat dilihat pada Gambar 11.

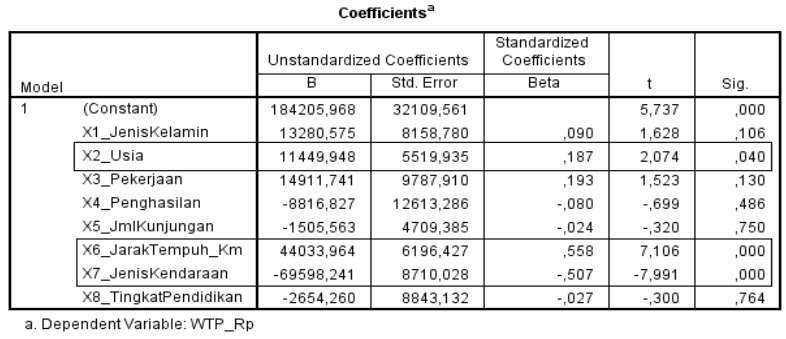

Gambar 11. Hasil Analisis Regresi

Penentuan standar error dalam penelitian adalah $8 \%$, maka nilai dari $\alpha=0,08$. Jika nilai sig dari nilai variabel-variabel bebas yang ditentukan kurang dari nilai $\alpha$ maka variabel bebas tersebut mempengaruhi terhadap variabel terkait (Y). Penentuan perbandingan antara variabel terkait dan hipotesa, nilai $B$ menunjukan positif berbanding lurus dengan hipotesa dan negatif berbanding terbalik dengan hipotesa.

Dari hasil analisa regresi Gambar 11. Dapat deketahui variabel yang mempengaruhi secara signifikan terhadap nilai WTP adalah variabel usia, jarak tempuh dan jenis kendaraan. Dari analisis regresi ini didapat persamaan sebagai berikut :

\section{$\mathrm{Y}=184205,968+13280,575 \mathrm{X} 1+$ $11449,948 X 2+14911,741 X 3$ - 8816,827X4 - $1505,563 X 5+44033,964 \times 6-69598,241 \times 7-$ 2654,260X8}

Keterangan :

$$
\begin{array}{ll}
\mathrm{Y} & =\mathrm{WTP}(\mathrm{Rp}) \\
\mathrm{X} 1 & =\text { Jenis kelamin } \\
\mathrm{X} 2 & =\text { Usia } \\
\mathrm{X} 3 & =\text { Pekerjaan } \\
\mathrm{X} 4 & =\text { Penghasilan } \\
\mathrm{X} 5 & =\text { Jumlah kunjungan } \\
\mathrm{X} 6 & =\text { Jarak Tempuh }(\mathrm{km}) \\
\mathrm{X} 7 & =\text { Jenis Kendaraan } \\
\mathrm{X} 8 & =\text { Tingkat Pendidikan }
\end{array}
$$

Pengujian dalam hipotesis pada perinsipnya adalah signifikansi. Siginifikansi merupakan taraf kesalahan yang didapatkan ketika pada saat menganalisis sampel penelitiannya. Peneliti 
melakukan penaksiran terhadapa parameter populasi berdasarkan data yang telah dikumpulkan dari paramater sampel penelitian.

Data yang tidak signifikan merupakan data yang tidak berhasil membuktikan keterikatan antara $\mathrm{X}$ dan $\mathrm{Y}$ artinya $\mathrm{X}$ tidak berpengaruh terhadap Y, sehingga data tersebut tidak berhasil membuktikan keterikatan.

Analisia regresi dapat dijadikan sebagai pengembangan terhadap fasilitas pariwisata khususnya Pantai Sawarna, untuk melakukan penentuan terhadap variabel bebas yang berpengaruh signifikan terhadap variabel terikat. Variabel yang berpengaruh terhadap nilai WTP diantaranya variabel usia, jarak tempuh dan jenis kendaraan, sehingga dengan cara pengembangan fasilitas pariwisata untuk mengikat daya tarik pengunjung terhadap variabel bebas yang berpengaruh signifikan. Pengunjung bertambah sesuai target yang ditentukan dan meningkatkan nilai WTP sehingga akan lebih cepat dana yang dibutuhkan untuk pengembangan terhadap aspek lingkungan.

\section{Kesimpulan}

Dari hasil perhitungan diatas dapat diketahui kesimpulan mengenai valuasi nilai ekonomi di Panati Sawarna dengan menggunakan Travel Cost Method. Nilai rata-rata WTP diketahui Rp. 93.672, sehingga diperoleh nilai ekonomi Pantai Sawarna adalah Rp. 6.722.558.424 / tahun Nilai surplus konsumen adalah $\mathrm{Rp}$. 5.164.066.252, analisis regresi yang di dapat bahwa variabel bebas X2 Usia, X6 jarak tempuh dan $\mathrm{X} 7$ jenis kendaraan yang berpengaruh signifikan terhadap nilai WTP. Nilai WTP akan relatif lebih tinggi bila lebih banyak dikunjungi pengunjung yang pertama kali berkunjung.

\section{Daftar Pustaka}

Dwiatmojo, A. (2015). Valuasi Nilai Ekonomi Wisata Pantai Amal: Aplikasi Travel
Cost Method (TCM). Researchgate, https://www.researchgate.net/publicatio n/305778000, diakses Agustus 2019.

Fauzi, A. (2004). Ekonomi sumber daya alam dan lingkungan: Teori dan aplikasi: Gramedia Pustaka Utama.

Hasbiah, A.W., Rochaeni, A., Sutopo, A.F. (2018). Analisis Kesediaan Membayar (Willingness to Pay) dan Kesediaan untuk Menerima Kompensasi (Willingnes to Accept) dari Keberadaan tempat Penampungan Sementara Ciwastra dengan Contingent Valuation Method. Infomatek: Jurnal Informatika, Manajemen dan Teknologi, 20(2), 107116.

Nugroho, P. S. (2010). Valuasi Ekonomi Wisata Pantai Glagah Dengan Pendekatan Biaya Perjalanan (Travel Cost) di Desa Glagah Kecamatan Temon Kabupaten Kulon Progo. Skripsi. Universitas Sebelas Maret.

Pearce, D. W. (2001). The economic value of forest ecosystems. Ecosystem health, 7(4), 284-296.

Djijono, Tarumingkeng, I. R. C., Coto, Z., dan Purwantara, B. (2002). Valuasi Ekonomi Menggunakan Metode Travel Cost Taman Wisata Hutan di Taman Wan Abdul Rachman, Propinsi Lampung. Makalah Pengantar Falsafah Sains. Institut Pertanian Bogor.

Sugiyono (2007). Metode Penelitian Kuantitatif Kualitatif dan $R \& D$. Bandung: Alfabeta.

Susilowati, M. I. (2009). Valuasi ekonomi manfaat rekreasi taman hutan raya Ir. $\mathrm{H}$. Djuanda dengan menggunakan pendekatan travel cost method. Skripsi. Institut Pertanian Bogor. 
Sthepanie, Y. (2015). Strategi Pengembangan Fasilitas Wisata Pantai Sawarna di Kabupaten Lebak Banten. Thesis. Universitas Pendidikan Indonesia.

Suparmoko, M. (2014). Ekonomi Sumber Daya Alam dan Lingkungan. Yogyakarta: BPFE.

Yustiani, Y.M., Emilia, Permana, A. (2017). Kajian Valuasi Ekonomi Wana Wisata
Taman Hutan Berdasarkan Pendapat Masyarakat Pengunjung (Studi Kasus Taman Hutan Tangkuban Perahu). Journal of Community Based Environmental Engineering and Management, 1(1), 1-9. 